\title{
High-Performance Liquid Chromatography Determination of Free Sugars and Mannitol in Mushrooms Using Corona Charged Aerosol Detection
}

\author{
Aneta Sławińska ${ }^{1,2} \cdot$ Ewa Jabłońska-Ryśs ${ }^{1,2}$ (1) Anna Stachniuk ${ }^{2}$ \\ Received: 9 January 2020 / Accepted: 22 September 2020 / Published online: 6 October 2020 \\ (C) The Author(s) 2020
}

\begin{abstract}
Refractive index detector is usually used in the analysis of sugars in mushrooms, which is characterized by poor sensitivity, reproducibility, and susceptibility to interference from co-eluting sample components. In the current study, identification and determination of free sugars in mushroom samples by high-performance liquid chromatography coupled to corona charged aerosol detector (HPLC-CAD) were presented for the first time. The best chromatographic separation was performed on a Shodex Asahipak NH2P-50 4E $5 \mu \mathrm{m}$ and mobile phase composed of $75 \%$ acetonitrile and $25 \%$ water with flow rate was $1 \mathrm{~mL} / \mathrm{min}$. The developed method offers good linearity in concentration range $0.001-0.01$ or $0.01-0.2 \mathrm{mg} / \mathrm{mL}$ for tested compounds with $R^{2}>0.99$. Limit of detection (LOD) for analytes was in the range of 7.1-120.2 ng on column. HPLC-CAD method showed very good reproducibility $(\mathrm{RSD}<5.1 \%)$. Fructose, mannitol, and glucose were detected in all examined mushroom samples. For white Agaricus bisporus, mannitol was the most abundant sugar $(7.575 \mathrm{mg} / \mathrm{g} \mathrm{dw})$, whereas trehalose for Pleurotus ostreatus $(3.426 \mathrm{mg} / \mathrm{g} \mathrm{dw})$. The developed method was successfully applied for quantification of free sugars and mannitol in mushrooms. The optimized method proved to be sensitive, reproducible, and accurate.
\end{abstract}

Keywords Free sugars $\cdot$ Polyols $\cdot$ Mushrooms $\cdot$ HPLC $\cdot$ CAD detector

\section{Introduction}

Mushrooms have been known to humanity for several thousand years and used for food and medicinal purposes (Wasser 2002). They are valued for their unique taste, aroma, and texture. However, the belief that mushrooms can be valuable and even used as functional foods is relatively new. Interest in edible and medicinal mushrooms is constantly growing, which is also confirmed by numerous scientific publications in the last two decades (Jabłońska-Ryś et al. 2019). Mushrooms are low in fat, rich in protein and fiber, are an important source of many vitamins $\left(\mathrm{B}_{1}, \mathrm{~B}_{2}, \mathrm{~B}_{12}, \mathrm{D}_{2}, \mathrm{C}\right.$, and $\mathrm{E})$, macro- and microelements, contain all exogenous amino

Ewa Jabłońska-Ryś

ewa.jablonska-rys@up.lublin.pl

1 Department of Fruits, Vegetables and Mushrooms Technology, University of Life Sciences in Lublin, Skromna 8, 20-704 Lublin, Poland

2 Department of Pathophysiology, Medical University of Lublin, Jaczewskiego 8b, 20-090 Lublin, Poland acids, fatty acids, and possess high antioxidant activity (Radzki et al. 2014; Sławińska et al. 2017). For these reasons nowadays, they are part of many food trends, such as diet food, vegetarianism and veganism, the searching for valuable micronutrients or the fifth taste, which is associated with their constantly increasing consumption (Kalač 2009).

The dry matter of mushrooms consists mainly of carbohydrates (from 35 to 70\%) (Guillamón et al. 2010). These compounds include polysaccharides such as $\beta$-glucans, mono- and disaccharides, sugar alcohols (polyols), glycogen, and chitin (Manzi et al. 2001). The most common representatives of mono-, disaccharides, and polyols in mushrooms are glucose, trehalose, and mannitol (Mocan et al. 2018). The content of glucose and trehalose is usually low; in turn, mannitol, depending on the species, may be present in higher amounts, from $0.2 \%$ to nearly $14 \%$ of dry matter (Jabłońska-Ryś et al. 2019).

The qualitative and quantitative analysis of sugars and polyols in mushrooms is very important for many reasons. First of all, free and soluble sugars and polyols are important part of chemical composition. What is more, these compounds, apart from free amino acids and 5'-nucleotides, are classified as non-volatile compounds that determine the typical mushroom taste (Phat et al. 2016). According to the authors Beluhan and 
Ranogajec (2011), the high content of sugars and polyols may affect the increase in the feeling of moderate sweet taste of mushrooms. In several scientific papers on mushrooms obtained from natural environments, it was emphasized that the analysis of the chemical composition would allow to create a data base providing the nutritional value and content of non-volatile compounds to improve the characteristics of unique species with high nutritional value and unique flavor (Jedidi et al. 2017).

In addition, the amount of free sugars and sugar alcohols can be an important indicator of storage conditions and preservation. Mushrooms are characterized by high perishability, which is associated with rapid loss of quality after harvest. This creates a problem in their distribution and sale as fresh raw material. Therefore, research is being conducted to extend the shelf life of fresh mushrooms. In this case, the polar compound profile is determined, which includes, in addition to organic acids, sugars and sugar alcohols, which are important indicators of preservation conditions (Cardoso et al. 2019; Fernandes et al. 2016). Determination of sugars in mushrooms at various stages of growth is also important for further processing in the flavors and fragrance industry. Mushrooms, depending on the stage of growth and morphological part (stipes or caps), are characterized by a different composition of sugars and organic acids, which mainly determine their flavor (Chen et al. 2015). The content and profile of sugars and polyols may differ significantly in fruiting bodies of the same species but obtained from different sources (Li et al. 2019; Stojković et al. 2014).

In many regions of the world, the spontaneous lactic fermentation process was traditionally used to preserve the fruiting bodies of wild-growing and cultivated edible mushrooms (Sõukand et al. 2015). Currently, there are no lacto-fermented mushrooms on the European market (Jabłońska-Ryś et al. 2019). However recently, a few publications have been published regarding the process of lactic acid fermentation of this raw material (Jabłońska-Ryś et al. 2016a, b; Khaskheli et al. 2015; Liu et al. 2016), and therefore, the current knowledge in this field needs to be systematized and broaden (Jabłońska-Ryś et al. 2019). Lactobacillus species (LAB) use free sugars found in food matrix as a source of energy (Das and Goyal 2012). Moreover, the preferences for simple sugars and polyols are different for LAB isolates used for controlled fermentation of plant material (Ye et al. 2019). Therefore, analysis of the composition of free sugars is important in assessing the suitability of mushroom fruiting bodies as a raw material for lactic acid fermentations. This knowledge will allow to choose the right LAB strains with the desired technological and functional properties.

Therefore, there is a need to develop a quick and simple method that can be used to determine free sugars in the food matrix which are mushrooms. The determination of these compounds is a challenge due to the lack of a chromophore and their polar structure. Various methods are used to determine these compounds. There are many publications describing the use of high-performance liquid chromatography (HPLC) (Agblevor et al. 2007), gas chromatography (GC) (Medeiros and Simoneit 2007), or capillary electrophoresis (CE) (Cao et al. 2004) techniques for sugar analysis. However, gas chromatography requires costly, time-consuming, and problematic sample derivatization prior to analysis. In turn, HPLC and capillary electrophoresis are commonly used analytical tools in combination with UV detection (Asthana et al. 2019). The absence of the sufficient chromophore in sugars and polyols prevents the use of a popular UV detector. For these reasons, the most common choice is the refractive index detector (RID) in sugar analysis. However, the disadvantage of this type of detector is poor sensitivity, reproducibility, and susceptibility to interference from co-eluting sample components (Calull et al. 1992; Grembecka et al. 2014). Several papers describe the use of evaporative lightscattering detector (ELSD) and charged aerosol detector (CAD) for the determination of sugars and sugar alcohols in various food matrices (Grembecka et al. 2014; Ma et al. 2014). Several works confirmed the higher sensitivity and precision of CAD and wider linear response range compared with ELSD (Eom et al. 2010; Jia et al. 2011; Vervoort et al. 2008).

Corona charged aerosol detector is a relatively cheap detection system, easy to use, and requiring only high nitrogen pressure (Ligor and Buszewski 2012). Since 2005, when the commercial use of CAD was first described (Gamache et al. 2005), many papers have been published regarding its application for the determination of many groups of compounds: vitamins, lipids, fatty acids, proteins, polymers, oligosaccharides, and sugars (Ligor and Buszewski 2012; Magnusson et al. 2015). Determination of sugars using CAD detector in food matrices has been described in several works (Gil et al. 2020; Grembecka et al. 2014; Márquez-Sillero et al. 2013); however, to date, no data is available regarding the use of it for mushroom samples. For this purpose, the universal RID detector is mainly used (Cardoso et al. 2019; Jedidi et al. 2017; Li et al. 2018). The application of HPAEC-PAD to determine these compounds in shiitake mushrooms has also been described (Chen et al. 2015).

The aim of the study was to develop and validate a new method using HPLC-CAD to determine free sugars (arabinose, fructose, glucose, sucrose, trehalose) and sugar alcohol (mannitol) in mushrooms. The method was applied to determine the above-mentioned compounds in fruiting bodies of various edible mushrooms with very good results. To our knowledge, this is the first work describing the use of HPLC-CAD for simultaneous determination of sugars and polyols in mushroom samples.

\section{Materials and Methods}

\section{Chemicals, Reagents, and Standards}

HPLC-grade acetonitrile 99.9\% was obtained from Merck (Darmstadt, Germany). All other reagents: (i) ethanol 96\% 
(analytical grade) was purchased from POCH (Gliwice, Poland); (ii) standards (analytical grade; all contents $>99 \%$ ): sugars (arabinose, fructose, glucose, sucrose, trehalose) and sugar alcohol (mannitol) were supplied by Sigma-Aldrich (Saint Louis, USA). All aqueous solutions were prepared using ultra pure water from the water purification system Direct-Q 3UV (Merck Millipore, Germany).

\section{Sample Preparation}

\section{Mushroom Materials}

The three most popular cultivated edible mushrooms in Poland, including white and brown button mushrooms (Agaricus bisporus (Lange) Sing.) and oyster mushrooms (Pleurotus ostreatus (Jacq.: Fr.) Kumm.) were purchased from local market in Lublin (eastern Poland) in May 2019, in an amount of about $2 \mathrm{~kg}$ of each species. The mushrooms were stored at $4{ }^{\circ} \mathrm{C}$ and processed within $12 \mathrm{~h}$ after purchase.

\section{Extraction Procedure}

About $300 \mathrm{~g}$ of fresh mushrooms were homogenized (Retsch GM200, Germany). Next suspensions of homogenized mushrooms ( $2 \mathrm{~g})$ in $8 \mathrm{~mL}$ of $80 \%$ ethanol were shaken at $150 \mathrm{rpm}$ for $0.5 \mathrm{~h}$ at $80^{\circ} \mathrm{C}$. After this time, the mixture was centrifuged for $15 \mathrm{~min}$ at $5000 \mathrm{~g}$ (MPV-350R, Poland). The supernatant was filtered and transferred to a $10-\mathrm{mL}$ volumetric flask and made up to $10 \mathrm{~mL}$ with $80 \%$ ethanol. Then, $1 \mathrm{~mL}$ of the resulting solution was taken and $3 \mathrm{~mL}$ of acetonitrile was added and put into the freezer for $24 \mathrm{~h}$. Next, the samples were centrifuged for $15 \mathrm{~min}$ at $16,000 \mathrm{~g}$ to get clear supernatants, which were used for subsequent analyses by HPLC-CAD. All assays were carried out in triplicate.

\section{Instrumentation and Chromatographic Conditions}

A Dionex Ultimate 3000 HPLC system coupled to a Corona Veo RS-charged aerosol detector (Germering, Germany) was used for chromatographic analysis. Nitrogen gas flow rate was regulated automatically and monitored by the CAD device. Gas was supplied by nitrogen generator V350 (F-DGSi,
France). The following CAD detector parameters have been set: nitrogen gas pressure: $35 \mathrm{psi}$; detector response $100 \mathrm{pA}$; noise filter: high. In addition, UV signal was registered at $210 \mathrm{~nm}$ by Dionex Ultimate 3000 RS Diode Array Detector. Separation was carried out using a Shodex Asahipak NH2P50 4E $5 \mu \mathrm{m}(4.6 \times 250 \mathrm{~mm})$ column with precolumn Asahipak NHZP-506 4A. The mobile phase of the optimized method composed of (A) $75 \%$ acetonitrile and (B) $25 \%$ water. The flow rate was $1 \mathrm{~mL} / \mathrm{min}$. The column temperature was maintained at $30{ }^{\circ} \mathrm{C}$. The injection volume was $20 \mu \mathrm{L}$ for standards and mushroom extracts. The chromatographic separation time was set to $22 \mathrm{~min}$. Chromoleon Dionex Software version 7.2 SR4 was used for data acquisition, instrument control, and data analysis.

\section{Method Validation}

For method calibration, series of working solutions with different concentrations of reference standards were prepared from stock solutions $(1 \mathrm{mg} / \mathrm{mL})$ by dilution with appropriate volume of water. Linearity was tested by triplicate injections of five different concentrations of the standards. The calibration curve for each sugar was obtained by plotting the area of the respective peaks versus the concentration of a compound. The slope, intercept, and the determination coefficients $\left(R^{2}\right)$ of calibration curves were determined by linear regression analysis.

To evaluate method performance, the inter-day precision and limit of detection (LOD) were determined. The inter-day precision was obtained by duplicate analysis of five concentrations of each analyte on three successive days and is expressed as relative standard deviations (RSD). Limit of detection was determined on the basis of response and slope of each regression equation at a signal to noise ratio $(\mathrm{S} / \mathrm{N})$ of 3 . The recoveries were tested by triplicate analyses of the lowest and the highest concentrations used in calibration studies.

\section{Determination of Free Sugars in Mushrooms}

The identification of sugars and sugar alcohol was performed by comparing the retention times of sample peaks with standards under the same chromatographic conditions described
Table 1 HPLC-CAD method parameters

\begin{tabular}{lllllll}
\hline Carbohydrate & $\begin{array}{l}\text { Retention } \\
\text { time [min] }\end{array}$ & Calibration curve & $R^{2}$ & $\begin{array}{l}\text { Calibration } \\
\text { range [mg/mL] }\end{array}$ & $\begin{array}{l}\text { RSD } \\
{[\%]}\end{array}$ & $\begin{array}{l}\text { LOD [ng on } \\
\text { column] }\end{array}$ \\
\hline Arabinose & 7.1 & $y=4.5105 x-0.0138$ & 0.997 & $0.01-0.2$ & 4.2 & 120.2 \\
Fructose & 8.0 & $y=108.2422 x-0.0084$ & 0.999 & $0.001-0.01$ & 4.6 & 7.2 \\
Mannitol & 9.1 & $y=93.0944 x-0.0113$ & 0.998 & $0.001-0.01$ & 5.1 & 7.1 \\
Glucose & 10.2 & $y=75.399 x-0.0099$ & 0.999 & $0.002-0.01$ & 4.4 & 11.4 \\
Sucrose & 14.1 & $y=107.9919 x-0.0145$ & 0.998 & $0.001-0.01$ & 4.1 & 9 \\
Trehalose & 17.3 & $y=91.1928 x-0.0097$ & 0.999 & $0.002-0.01$ & 4.8 & 14.7 \\
\hline
\end{tabular}


Fig. 1 Overlaid HPLC-CAD chromatograms of arabinose, fructose, mannitol, glucose, sucrose, and trehalose. Column: Shodex Asahipak NH2P-50 4E $5 \mu \mathrm{m}(4.6 \times 250 \mathrm{~mm})$, mobile phase: $25 \%$ water, $75 \%$ acetonitrile, flow $1 \mathrm{~mL} / \mathrm{min} ; 1 \mu \mathrm{g}$ of each saccharide injected on column

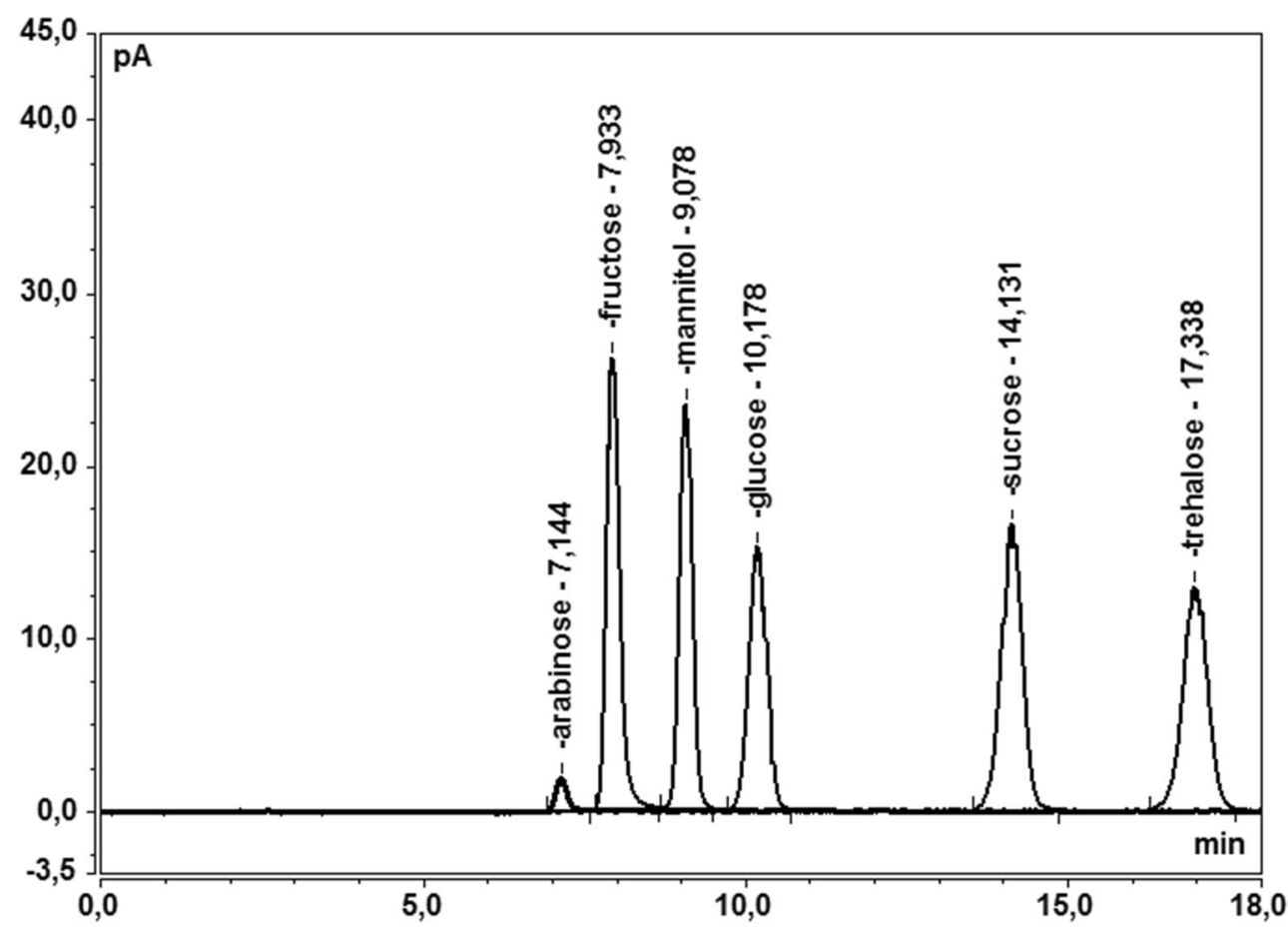

in section "Instrumentation and Chromatographic Conditions". The quantification was carried out by the internal standard method. The results were expressed in $\mathrm{mg}$ per $1 \mathrm{~g}$ of dry weight (dw).

\section{Results and Discussion}

\section{Method Validation}

Optimized and applied parameters of the chromatographic separation (composition of the mobile phase, flow rate, and column temperature) allowed to obtain negligible baseline noise, indicating complete solvent evaporation, and to quantify the compounds tested. Separation time was initially carried out for $40 \mathrm{~min}$; however, all analyzed compounds were separated in less than $22 \mathrm{~min}$. A similar separation time (19 min) of soluble sugars and mannitol in cocoa was reported by Gil et al. (2020).

The data concerning method validation are summarized in Table 1. An example of an overlaid HPLC-CAD chromatograms of standards ( $1 \mu \mathrm{g}$ of each saccharide injected on column) is shown in Fig. 1. All analytes were baseline separated.

Corona CAD response is nonlinear at range of orders of magnitude, but its signal can be close to linear in smaller ranges (Grembecka et al. 2014). The calibration curves of all six analytes showed good linearity $\left(R^{2}>0.99\right)$. The average of triplicate determinations for each level was used. The LODs $(\mathrm{S} / N=3)$ for analyzed compounds were in the range of 7.1$120.2 \mathrm{ng}$ on column. The results indicated highly satisfactory inter-day precision of peak areas (4.1-5.1\% RSD).
The recoveries of analytes were tested and were found to be in the range of $96-101 \%$. The relative standard deviation for recoveries did not excide $7 \%$.

One of the latest papers by Pitsch and Weghuber (2019) presents the results of the determination of sugars and polyols in food and beverages using HILIC chromatography coupled with CAD detector. The obtained RDS values were $<5 \%$ (ranged from 0.01 to $4.78 \%$ ), and it was similar to those obtained in our research. The regression coefficients were above 0.99 for all soluble sugars and mannitol in work by Gil et al. (2020). Also, in one of the first works on the determination of sugars and polyols in food using a CAD detector, all standard curves were linear (at range $1-100 \mu \mathrm{g} / \mathrm{mL}$ ) except the one of sucrose, which linearity authors obtained in a logarithmic coordinate system. Pitsch and Weghuber (2019) used a different method to calculate linearity than linear calibrations. They obtained good correlation coefficients $\left(R^{2} \geq 0.999\right)$ for nonlinear calibration cures (from 10.0 to $1000 \mathrm{mg} / \mathrm{mL}$ ), which, as the

Table 2 Carbohydrate content in mushrooms $[\mathrm{mg} / \mathrm{g} \mathrm{dw}]$

\begin{tabular}{llll}
\hline Carbohydrate & A. bisporus white & A. bisporus brown & P. ostreatus \\
\hline Arabinose & $<$ LOD & $<$ LOD & $<$ LOD \\
Fructose & 0.432 & 0.213 & 0.149 \\
Mannitol & 7.575 & 5.409 & 0.633 \\
Glucose & 0.374 & 0.928 & 1.366 \\
Sucrose & $<$ LOD & $<$ LOD & $<$ LOD \\
Trehalose & $<$ LOD & 1.032 & 3.426 \\
\hline
\end{tabular}


Fig. 2 HPLC-CAD

chromatogram of extract from A. bisporus white (a), A. bisporus brown (b), and P. ostreatus (c).

Column: Shodex Asahipak

NH2P-50 4E $5 \mu \mathrm{m}(4.6 \times$

$250 \mathrm{~mm}$ ), mobile phase: $25 \%$

water, $75 \%$ acetonitrile, flow

$1 \mathrm{~mL} / \mathrm{min}$
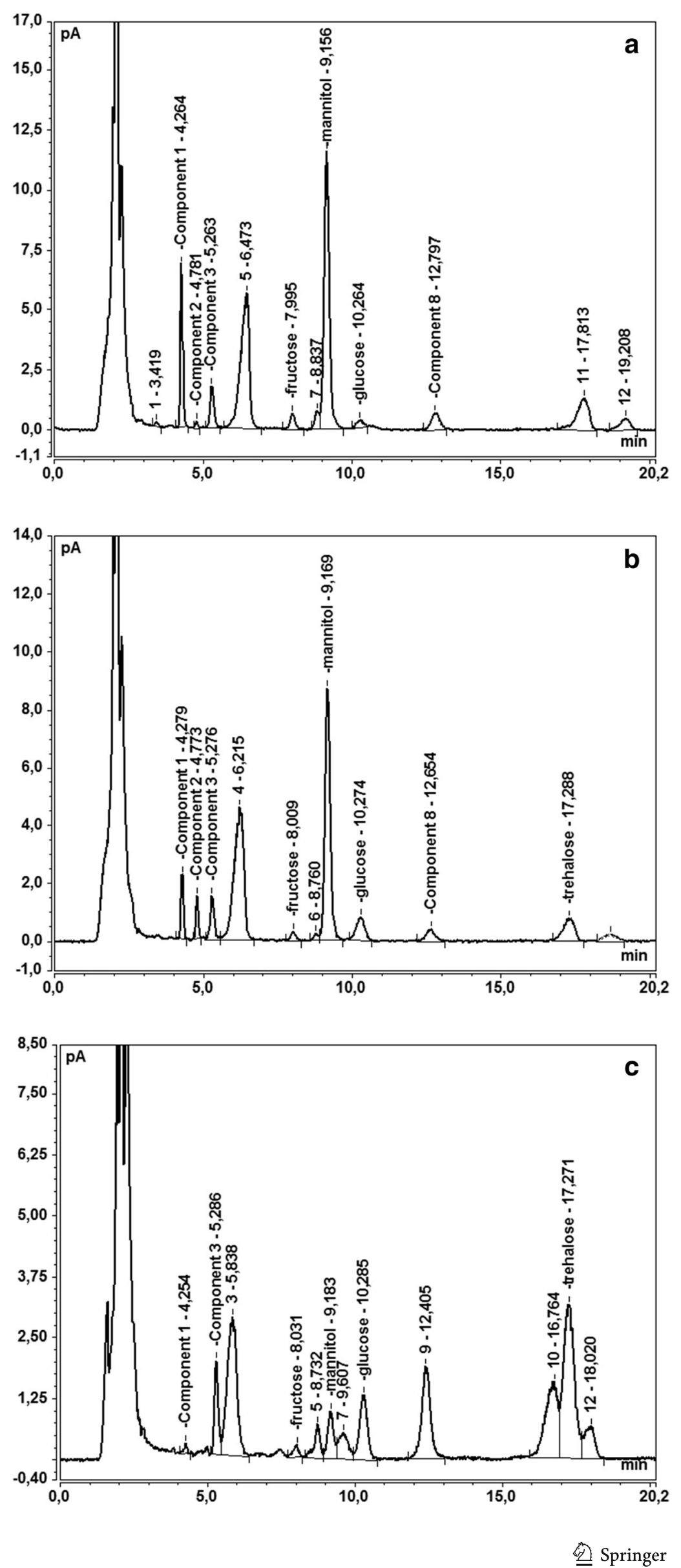
authors explain, gives more flexibility in routine analysis. In turn, LOD values presented in the article by Pitsch and Weghuber (2019) were in range of $0.247-2.675 \mathrm{mg} / \mathrm{mL}$, while at work by Gil et al. (2020), LOD values were determined at $0.06-0.15 \% w / w$ and $0.04-0.19 \% w / w$ for each analyte estimated in dried and fermented cocoa beans.

Fu et al. in the paper from 2020 presented the results of the separation of sugar isomers and anomers using hydrophilic interaction liquid chromatography (HILIC) with CAD or tandem mass spectrometry. The authors propose this method as useful especially for profiling mono- and disaccharides in the field of glycometabolomics. Their work presents the chromatographic separation of isomeric carbohydrates including isomeric hexoses, pentoses, and disaccharides employing the new commercial HILIC column, by varying the temperature and $\mathrm{pH}$ of the chromatographic separation that are important for the separation of sugar isomers. Low temperature (10 or $15^{\circ} \mathrm{C}$ ) in acidic mobile phase proved to be the best conditions for chromatographic separation.

\section{Quantification of Free Sugars in Edible Mushrooms}

The usefulness of the developed analytical method has been confirmed on real samples of the most popular edible cultivated mushrooms in Poland. Figure 2 shows examples of chromatograms for the mushroom samples with described peaks of identified sugars. The other unidentified compounds coextracted are also visible on the chromatograms, which have been designated as component 1,2 etc. with the retention times marked. Considering tested sugar compositions (Table 2), fructose, mannitol, and glucose were detected in all the samples. For A. bisporus, white and brown mannitol was the most abundant sugar $(7.575$ and $5.409 \mathrm{mg} / \mathrm{g} \mathrm{dw}$, respectively), whereas trehalose for P. ostreatus $(3.426 \mathrm{mg} / \mathrm{g}$ $\mathrm{dw})$. A small amount of trehalose $(1.032 \mathrm{mg} / \mathrm{g} \mathrm{dw})$ was also found in A. bisporus brown, while this disaccharide was observed below LOD in A. bisporus white.

The accumulations of the disaccharide trehalose and sugar alcohol mannitol in the fruiting bodies of other species were reported in other research. Among the three compounds analyzed: mannitol, trehalose, and glucose, only mannitol (9.93 g/ $100 \mathrm{~g} \mathrm{dw}$ ) was found in the fruiting bodies of wild button mushrooms harvested in Tunisia (Jedidi et al. 2017). As reported by Reis et al. (2012), a similar profile of sugars in cultivated mushrooms was obtained as in our study. In white and brown button mushrooms, the highest content of mannitol was detected (5.16 and 4.01 per $100 \mathrm{~g} \mathrm{fw}$, respectively), while the main sugar in the fruiting bodies of oyster $(4.42 \mathrm{~g} / 100 \mathrm{~g}$ $\mathrm{fw})$ and king oyster mushrooms $(8.01 \mathrm{~g} / 100 \mathrm{~g}$ fw) was trehalose. Except for a small amount of sucrose $(0.03 \mathrm{~g} / 100 \mathrm{~g} \mathrm{fw})$ in king oyster, this compound was not found in other mushrooms, whereas in all samples, a small amount of fructose was identified (from 0.01 to $0.04 \mathrm{~g} / 100 \mathrm{~g} \mathrm{fw}$ ). Another work confirms that mannitol was found as being the most abundant sugar (36 g/100 g dw) in A. bisporus Portobello, and a lower content of fructose $(0.6 \mathrm{~g} / 100 \mathrm{~g} \mathrm{dw})$ and disaccharide trehalose (1.6 g/100 g dw) was detected (Cardoso et al. 2019).

\section{Conclusions}

The HPLC-CAD-developed method is the first of its kind described in the scientific literature that allows simultaneous and accurate determination of six compounds without chromophore groups, sugars (trehalose, glucose, fructose, sucrose, and arabinose) and sugar alcohol - mannitol in mushroom in $22 \mathrm{~min}$. The results obtained from the analyzed real samples showed the possibility of the proposed method to be used for routine analysis of sugars and polyols in mushrooms only with one injection of the sample. The analysis results obtained for examined mushroom samples were in good agreement with those presented by other authors. Furthermore, method validation parameters for the analysis of sugars using CAD demonstrated very good linearity and reproducibility and good limits of detection.

Funding Project financed under the program of the Minister of Science and Higher Education under the name "Regional Initiative of Excellence" in 2019-2022 project number 029/RID/2018/19 funding amount 11,927,330.00 PLN.

\section{Compliance with Ethical Standards}

Conflict of Interest Aneta Sławińska declares that she has no conflict of interest. Ewa Jabłońska-Ryś declares that she has no conflict of interest. Anna Stachniuk declares that she has no conflict of interest.

Ethical Approval This article does not contain any studies with human participants or animals performed by any of the authors.

Informed Consent Informed consent is not applicable to this study.

Open Access This article is licensed under a Creative Commons Attribution 4.0 International License, which permits use, sharing, adaptation, distribution and reproduction in any medium or format, as long as you give appropriate credit to the original author(s) and the source, provide a link to the Creative Commons licence, and indicate if changes were made. The images or other third party material in this article are included in the article's Creative Commons licence, unless indicated otherwise in a credit line to the material. If material is not included in the article's Creative Commons licence and your intended use is not permitted by statutory regulation or exceeds the permitted use, you will need to obtain permission directly from the copyright holder. To view a copy of this licence, visit http://creativecommons.org/licenses/by/4.0/.

\section{References}

Agblevor FA, Hames BR, Schell D, Chum HL (2007) Analysis of biomass sugars using a novel HPLC method. Appl Biochem Biotechnol 136:309-326. https://doi.org/10.1007/s12010-007-9028-4 
Asthana C, Peterson GM, Shastri M, Patel RP (2019) Development and validation of a novel high performance liquid chromatographycoupled with Corona charged aerosol detector method for quantification of glucosamine in dietary supplements. PLoS One 14: e0216039. https://doi.org/10.1371/journal.pone.0216039

Beluhan S, Ranogajec A (2011) Chemical composition and non-volatile components of Croatian wild edible mushrooms. Food Chem 124: 1076-1082. https://doi.org/10.1016/j.foodchem.2010.07.081

Calull M, Marce R, Borrull F (1992) Determination of carboxylic acids, sugars, glycerol and ethanol in wine and grapemust by ion-exchange high performance liquid chromatography with refractive index detection. J Chromatogr A 590:215-222. https://doi.org/10.1016/ 0021-9673(92)85384-6

Cao Y, Wang Y, Chen X, Ye J (2004) Study on sugar profile of rice during ageing by capillary electrophoresis with electrochemical detection. Food Chem 86:131-136. https://doi.org/10.1016/j. foodchem.2003.12.004

Cardoso RVC, Fernandes Â, Barreira JCM, Verde SC, Antonio AL, Gonzaléz-Paramás AM, Barros L, Ferreira ICFR (2019) Effectiveness of gamma and electron beam irradiation as preserving technologies of fresh Agaricus bisporus Portobello: a comparative study. Food Chem 278:760-766. https://doi.org/10.1016/j. foodchem.2018.11.116

Chen W, Li W, Yang Y, Yu H, Zhou S, Feng J, Li X, Liu Y (2015) Analysis and evaluation of tasty components in the pileus and stipe of Lentinula edodes at different growth stages. J Agric Food Chem 63:795-801. https://doi.org/10.1021/jf505410a

Das D, Goyal A (2012) Lactic acid bacteria in food industry. In: Satyanarayana T, Johri BN (eds) Microorganisin sustainable agriculture and biotechnology. Springer, Dordrecht, pp 757-772

Eom HY, Park S, Kim MK, Suh JH, Yeom H, Min JW, Kim U, Lee J, Youm J, Han SB (2010) Comparison between evaporative light scattering detection and charged aerosol detection for the analysis of saikosaponins. J Chromatogr A 1217:4347-4354. https://doi.org/ 10.1016/j.chroma.2010.04.047

Fernandes Â, Barreira JCM, Antonio AL, Oliveira MBPP, Martins A, Ferreira ICFR (2016) Extended use of gamma irradiation in wild mushrooms conservation: validation of $2 \mathrm{kGy}$ dose to preserve their chemical characteristics. LWT Food Sci Technol 67:99-105. https:// doi.org/10.1016/j.lwt.2015.11.038

Fu X, Cebo M, Ikegami T, Lämmerhofer M (2020) Separation of carbohydrate isomers and anomers on poly- $\mathrm{N}-(1 \mathrm{H}$-tetrazole-5-yl)methacrylamide-bonded stationary phase by hydrophilic interaction chromatography as well as determination of anomer interconversion energy barriers. J Chromatogr A 1620:460981. https://doi.org/10. 1016/j.chroma.2020.460981

Gamache PH, McCarthy RS, Freeto SM, Asa DJ, Woodcock MJ, Laws K, Cole RO (2005) HPLC analysis of non-volatile analytes using charged aerosol detection. LC-GC Eur 18:345-354

Gil M, Llano S, Jaramillo Y, Quijano J, Londono-Londono J (2020) Matrix effect on quantification of sugars and mannitol developed during the postharvest of cocoa: an alternative method for traceability of aroma precursors by liquid chromatography with an evaporative detector. J Food Sci Technol 57:210-221. https://doi.org/10. 1007/s13197-019-04049-1

Grembecka M, Lebiedzińska A, Szefer P (2014) Simultaneous separation and determination of erythritol, xylitol, sorbitol, mannitol, maltitol, fructose, glucose, sucrose and maltose in food products by high performance liquid chromatography coupled to charged aerosol detector. Microchem J 117:77-82. https://doi.org/10.1016/j.microc. 2014.06.012

Guillamón E, García-Lafuente A, Lozano M, Darrigo M, Rostagno MA, Villares A, Martínez JA (2010) Edible mushrooms: role in the prevention of cardiovascular diseases. Fitoterapia 81:715-723. https:// doi.org/10.1016/j.fitote.2010.06.005
Jabłońska-Ryś E, Sławińska A, Radzki W, Gustaw W (2016a) Evaluation of the potential use of probiotic strain Lactobacillus plantarum 299v in lactic fermentation of button mushroom fruiting bodies. Acta Sci Pol Technol Aliment 15:399-407. https://doi.org/10.17306/J.AFS. 2016.4.38

Jabłońska-Ryś E, Sławińska A, Szwajgier D (2016b) Effect of lactic acid fermentation on antioxidant properties and phenolic acid contents of oyster (Pleurotus ostreatus) and chanterelle (Cantharellus cibarius) mushrooms. Food Sci Biotechnol 25:439-444. https://doi.org/10. 1007/s10068-016-0060-4

Jabłońska-Ryś E, Skrzypczak K, Sławińska A, Radzki W, Gustaw W (2019) Lactic acid fermentation of edible mushrooms: tradition, technology, current state of research: a review. Compr Rev Food Sci Food Saf 18:655-669. https://doi.org/10.1111/1541-4337. 12425

Jedidi IK, Ayoub IK, Philippe T, Bouzouita N (2017) Chemical composition and nutritional value of three Tunisian wild edible mushrooms. J Food Meas Charact 11:2069-2075. https://doi.org/10. 1007/s11694-017-9590-6

Jia S, Park JH, Lee J, Kwon SW (2011) Comparison of two aerosol-based detectors for the analysis of gabapentin in pharmaceutical formulations by hydrophilic interaction chromatography. Talanta 85:23012306. https://doi.org/10.1016/j.talanta.2011.04.012

Kalač P (2009) Chemical composition and nutritional value of European species of wild growing mushrooms: a review. Food Chem 113:9 16. https://doi.org/10.1016/j.foodchem.2008.07.077

Khaskheli SG, Zheng W, Sheikh SA, Khaskheli AA, Liu Y, Wang YF, Huang W (2015) Effect of processing techniques on the quality and acceptability of Auricularia auricula mushroom pickle. J Food Nutr Res 3:46-51. https://doi.org/10.12691/jfnr-3-1-8

Li X, Guo Y, Zhuang Y, Qin Y, Sun L (2018) Nonvolatile taste components, nutritional values, bioactive compounds and antioxidant activities of three wild Chanterelle mushrooms. Int J Food Sci Technol 53:1855-1864. https://doi.org/10.1111/ijfs.13769

Li J, Liang H, Qiao P, Su K, Liu P, Guo S, Chen J (2019) Chemical composition and antioxidant activity of Tuber indicum from different geographical regions of China. Chem Biodivers 16:e1800609. https://doi.org/10.1002/cbdv.201800609

Ligor M, Buszewski B (2012) Study of xanthophyll concentration in spinach leaves by means of HPLC coupled with UV-VIS and Corona CAD detectors. Food Anal Methods 5:388-395. https:// doi.org/10.1007/s12161-011-9256-7

Liu Y, Xie X, Ibrahim SA, Khaskheli SG, Yang H, Wang Y, Huang W (2016) Characterization of Lactobacillus pentosus as a starter culture for the fermentation of edible oyster mushrooms (Pleurotus spp.). LWT Food Sci Technol 68:21-26. https://doi.org/10.1016/j.lwt. 2015.12.008

Ma C, Sun Z, Chen C, Zhang L, Zhu S (2014) Simultaneous separation and determination of fructose, sorbitol, glucose and sucrose in fruits by HPLC-ELSD. Food Chem 145:784-788. https://doi.org/10. 1016/j.foodchem.2013.08.135

Magnusson L, Risley DS, Koropchak JA (2015) Aerosol-based detectors for liquid chromatography. J Chromatogr A 1421:68-81. https://doi. org/10.1016/j.chroma.2015.07.045

Manzi P, Aguzzi A, Pizzoferrato L (2001) Nutritional value of mushrooms widely consumed in Italy. Food Chem 73:321-325. https:// doi.org/10.1016/S0308-8146(00)00304-6

Márquez-Sillero I, Cárdenas S, Valcárcel M (2013) Comparison of two evaporative universal detectors for the determination of sugars in food samples by liquid chromatography. Microchem J 110:629 635. https://doi.org/10.1016/j.microc.2013.07.008

Medeiros PM, Simoneit BRT (2007) Analysis of sugars in environmental samples by gas chromatography-mass spectrometry. J Chromatogr A 1141:271-278. https://doi.org/10.1016/j.chroma.2006.12.017

Mocan A, Fernandes Â, Barros L, Crișan G, Smiljković M, Soković M, Ferreira ICFR (2018) Chemical composition and bioactive 
properties of the wild mushroom: Polyporus squamosus (Huds.) Fr: a study with samples from Romania. Food Funct 9:160-170. https:// doi.org/10.1039/c7fo01514c

Phat C, Moon B, Lee C (2016) Evaluation of umami taste in mushroom extracts by chemical analysis, sensory evaluation, and an electronic tongue system. Food Chem 192:1068-1077. https://doi.org/10. 1016/j.foodchem.2015.07.113

Pitsch J, Weghuber J (2019) Hydrophilic interaction chromatography coupled with charged aerosol cetection for simultaneous quantitation of carbohydrates, polyols and ions in food and beverages. Molecules 24:4333. https://doi.org/10.3390/molecules24234333

Radzki W, Sławińska A, Jabłońska-Ryś E, Gustaw W (2014) Antioxidant capacity and polyphenolic content of dried wild edible mushrooms from Poland. Int J Med Mushrooms 16:65-75. https://doi.org/10. 1615/IntJMedMushr.v16.i1.60

Reis FS, Barros L, Martins A, Ferreira ICFR (2012) Chemical composition and nutritional value of the most widely appreciated cultivated mushrooms: an inter-species comparative study. Food Chem Toxicol 50:191-197. https://doi.org/10.1016/j.fct.2011.10.056

Sławińska A, Fornal E, Radzki W, Jabłońska-Ryś E, Parfieniuk E (2017) Vitamin $\mathrm{D}_{2}$ stability during the refrigerated storage of ultraviolet $\mathrm{B}-$ treated cultivated culinary-medicinal mushrooms. Int J Med Mushrooms 19:249-255. https://doi.org/10.1615/ IntJMedMushrooms.v19.i3.70
Sõukand R, Pieroni A, Biró M, Dénes A, Dogan Y, Hajdari A, Kalle R, Reade B, Mustafa B, Nedelcheva A, Quave CL, Łuczaj Ł (2015) An ethnobotanical perspective on traditional fermented plant foods and beverages in Eastern Europe. J Ethnopharmacol 170:284-296. https://doi.org/10.1016/j.jep.2015.05.018

Stojković DS, Barros L, Calhelha RC, Glamočlija J, Ćirić A, Van Griensven LJLD, Soković M, Ferreira ICFR (2014) A detailed comparative study between chemical and bioactive properties of Ganoderma lucidum from different origins. Int J Food Sci Nutr 65:42-47. https://doi.org/10.3109/09637486.2013.832173

Vervoort N, Daemen D, Török G (2008) Performance evaluation of evaporative light scattering detection and charged aerosol detection in reversed phase liquid chromatography. J Chromatogr A 1189:92100. https://doi.org/10.1016/j.chroma.2007.10.111

Wasser S (2002) Medicinal mushrooms as a source of antitumor and immunomodulating polysaccharides. Appl Microbiol Biotechnol 60:258-274. https://doi.org/10.1007/s00253-002-1076-7

Ye J, Huang L, Terefe NS, Augustin MA (2019) Fermentation-based biotransformation of glucosinolates, phenolics and sugars in retorted broccoli puree by lactic acid bacteria. Food Chem 286:616-623. https://doi.org/10.1016/j.foodchem.2019.02.030

Publisher's Note Springer Nature remains neutral with regard to jurisdictional claims in published maps and institutional affiliations. 